\title{
Family system characteristics from the obese child and parent perspective - a pilot study
}

\author{
Agnieszka Pasztak-Opilka ${ }^{1}$ Agnieszka Zachurzok², Ewa Malecka-Tendera² \\ ${ }^{1}$ Institute of Psychology, Faculty of Pedagogy and Psychology, University of Silesia, Katowice, Poland \\ 2Department of Pediatrics and Pediatric Endocrinology, School of Medicine in Katowice, Medical University of Silesia, \\ Katowice, Poland
}

\begin{abstract}
Objective: The aim of the study was to assess family system functioning in obese children from the perspective of child and parent.

Material and methods: Forty-six dyads (child-parent) were included into the study. Children group comprises of $48 \%$ boys and $52 \%$ girls, aged $11-18$ years (13.0 \pm 1.9 years), with simple obesity (BMI $>97$ percentile, BMI $\mathrm{z}$-score $2.1 \pm 0.3)$. In parents' group, $87 \%$ mothers and $13 \%$ fathers were examined. The weight and height were measured, BMI, and BMI $z$-score were calculated, and Polish version of Family Adaptability and Cohesion Evaluation Scales by D. Olson was performed in all dyads. In parents, a questionnaire formulated for the research was applied.
\end{abstract}

Results: Only parents of 2 (7\%) children had BMI within the normal range. According to the information given in the questionnaire, problems with weight in the family were declared by significantly less parents: 22 (48\%). In parent's opinion, low physical activity (87\%) and inappropriate diet (87\%) were the most common reasons for obesity, whereas psychological problems (65\%) and poor physical fitness (65\%) were the most its common consequences. The most effective therapeutic factors were to comply with diet (87\%), increase physical activity (72\%), and change of lifestyle of the child (65\%). The families were assessed as balanced according to $57 \%$ of children and $30 \%$ of parents $(p=0.01)$. Also, cohesion index and main index were significantly higher in children's perception then parents' $(p=0.02, p=0.004)$.

Conclusions: Most of parents, in majority also obese, underline the need of change only in child's functioning; they do not see the need to change of their own habits and deny the presence of obesity in the family. Moreover, parents perceived cohesion in their families lower than children. Our observation confirms that obesogenic family with some aberration in its functioning could lead to many difficulties in treatment of obesity.

Key words: childhood obesity, family system, cohesion, flexibility, circumplex model.

\section{Introduction}

Childhood obesity has become serious public health problem in today's World. It is well known that it leads to many consequences, both medical: metabolic syndrome, polycystic ovary syndrome, type 2 diabetes, cardiovascular diseases, breathing problems, non-alcoholic fatty liver disease, musculoskeletal disorders, obesity related cancer as well as psychological and emotional problems, especially low self-esteem, depression, and social rejection [1]. The purpose of excessive body weight is usually seen in caloric reach diet and poor physical activity. However, its background is much more complex, involving genetic and epigenetic factors, but also social and family habits as well as personal temperamental features and psychological problems. The consequences of child obesity reach beyond an individual, tracking also next generations. Being an obese child means higher risk of becoming an obese adult and being an obese parent means increased risk of obesity in children $[1,2]$.

The theoretical conception of Circumplex Model of Marital and Family Systems by D. Olson is based on 
two main dimensions: cohesion and flexibility, and the ancillary one: communication [3,4]. The cohesion and flexibility are continuous dimension, reaching from very low, average to high levels in each family. The essential hypothesis of the model is based on curvilinear relationship between the level of cohesion and flexibility and family functioning. It is assumed that balanced cohesion and balanced flexibility serve the best for proper family functioning, and their extremely low and high values lead to dysfunctional, problematic functioning of the family $[3,4]$. The cohesion characterizes the emotional bond between members of the family, the type of psychological borders, and coalitions within the family, but also the way of spending time together, shared hobbies, the way of making important decisions as well relations with the persons not being family members. The extremely low level of cohesion is the disengagement, extremely high - enmeshment. Family flexibility refers to a family's ability to adapt leaderships, roles, relationships, negotiations, and rules in response to events or stress. Like the cohesion, flexibility is also assessed on a continuum scale of low (rigidity) to high (chaos) levels of stability versus change $[3,4]$.

Family communication is considered to be a facilitating dimension, which impacts family cohesion and flexibility. It is an ability to intercommunicate positively within the family and reach effective or ineffective level. The only effective level of communication skills, through the changes in flexibility and cohesion levels, allows to adopt to developmental and situational requirements of the family system. Additional dimension added to the concept is family life satisfaction. As Olson assumed, effective communication correlates positively with balanced family and high level of family life satisfaction, negatively with unbalanced family functioning. Moreover, balanced families are characterized with higher level of family life satisfaction than unbalanced families $[3,4]$.

The aim of the study was to assess the family system functioning in obese children from the perspective of obese children and their parents, and to compare these perceptions.

\section{Material and methods}

Sixty-two dyads, obese child and his/her parent were enrolled into the study. All children were patients of the Outpatient Obesity Clinic of Upper Silesian Hospital for Children. Forty-six pairs were included into the statistical analysis due to completeness of given data. Children group comprises 22 (48\%) boys and 24 (52\%) girls, aged $11.0-18.0$ years $(13.0 \pm 1.9$ years $)$, with simple obesity and body mass index (BMI) exceeding 97 percentiles (BMI $z$-score $2.1 \pm 0.3$, range 1.5 -2.9). In the parent group, 40 (87\%) mothers and $6(13 \%)$ fathers were examined. The exclusion criteria in a child were: known psychiatric disturbances, endocrine disorders causing obesity, usage of medications known to influence the body weight status in last 3 months, and other medical condition, which could influence body weight. In all dyads, detailed information about the length of being obese in child, the age, weight, and height of parents as well as obesity and obesity-related comorbidities in the family were collected. In children, weight was measured with Seca scale with a precision of $100 \mathrm{~g}$ and height measured with Harpender stadiometer to $0.1 \mathrm{~cm}$. BMI and BMI $z$-score were calculated.

The study was conducted according to the Helsinki declaration and approved by the Ethics Committee of the Medical University of Silesia. Informed consent was obtained from each subject and parent or guardian.

In all dyads (the child and the parent), Polish version (by Margasinski) of Family Adaptability and Cohesion Evaluation Scales (FACES IV) by D. Olson was performed. The questionnaire was answered during unlimited time, but the average time of completion was about 20 minutes. It is based on six scales, falling within 42 items: two scales of balanced cohesion and balanced flexibility, and four scales of extreme levels (disengagement, enmeshment, rigidity, chaos). Moreover, 10 items from Family Communication Scale and 10 items from Family Satisfaction Scale were added to this questionnaire. The items were evaluated in 5-grade Likert's scale. Next, in all parents, the questionnaire formulated for our research was performed. It contained the questions about: age and gender of the parent, obesity in the family, the parent's opinion about the obesity risk factors in child, its consequences, and treatment possibilities.

Auxological data and the questionnaires results were compared using the Statistica 12.0 PL. All values were expressed as mean (standard deviation) for normal or median (interquartile range) for skewed distribution. Comparison between groups was performed using Student $t$-test for normally distributed data and Mann-Whitney $U$ test for skewed distributions. $P$ value $<0.05$ was considered statistically significant.

\section{Results}

The clinical characteristics of obese children and their parents is presented in Table 1. The number of girls and boys enrolled into the study was similar (24 vs. 22 subjects, $p>0.05)$. Most of the parents had an excessive body weight: 16 (35\%) mothers were overweight, 18 (39\%) were obese, and only $12(26 \%)$ had BMI between $18.5-24.9 \mathrm{~kg} / \mathrm{m}^{2}$. In fathers, 20 (43\%) were overweight, 18 (39\%) were obese, and only 8 fathers (18\%) had normal BMI. Parents of only two $(7 \%)$ children had BMI within the normal range; in 16 (32\%) children, at least one parent was obese or overweight and in $28(61 \%)$, both parents had 
excessive weight. According to the information given in the questionnaire, excessive weight in the family were declared by significantly less parents: $22(48 \%, p=0.001)$ (Table 2). The low physical activity (40 parents, $87 \%$ ), inappropriate feeding (40 parents, $87 \%$ ), and genetic factors (22 parents, $48 \%$ ) were given as the most common causes of child's obesity. Less common were: family prob- lems (10 parents, 22\%) and school trouble (5 parents, $11 \%$ ). Psychological problems (30 parents, 65\%), poor physical fitness (30 parents, 65\%), and medical disorders (19 parents, $41 \%$ ) were the most common consequences of childhood obesity according to parents. Less common was premature death (13 parents, 28\%). Other consequences of obesity were pronounced by girls' and other

Table 1. Clinical characteristic of children and their parents

\begin{tabular}{|l|c|c|c|}
\hline & Obese children, $n=46$ & Boys, $n=22$ & Girls, $n=24$ \\
\hline Age (years) & $13.0 \pm 1.9$ & $13.0 \pm 1.9$ & $13.0 \pm 1.9$ \\
\hline BMI z-score & $2.1 \pm 0.3$ & $2.2 \pm 0.5$ & $1.9 \pm 0.3$ \\
\hline \begin{tabular}{l} 
Mother \\
\hline Age (years)
\end{tabular} & $43.0 \pm 6.0$ & & \\
\hline BMI (kg/m 2$)$ & $28.8 \pm 4.4$ & $28.8 \pm 4.4$ & $42.0 \pm 6.2$ \\
\hline \begin{tabular}{l} 
Father \\
\hline Age (years)
\end{tabular} & $45.2 \pm 6.7$ & $45.7 \pm 6.1$ & $27.3 \pm 4.4$ \\
\hline BMI (kg/m $)$ & $29.7 \pm 5.3$ & $29.6 \pm 3.3$ & $44.8 \pm 7.5$ \\
\hline
\end{tabular}

Table 2. Selected data from parents' questionnaire

\begin{tabular}{|c|c|c|c|c|}
\hline & & $\begin{array}{c}\text { Obese children, } \\
n=46(\%)\end{array}$ & Boys, $n=22(\%)$ & Girls, $n=24(\%)$ \\
\hline \multirow{2}{*}{$\begin{array}{l}\text { For how long the child has } \\
\text { been having excessive weight? }\end{array}$} & $1-3$ years & $8(17)$ & $3(14)$ & $5(21)$ \\
\hline & More than 3 years & $38(83)$ & $19(86)$ & $19(79)$ \\
\hline \multirow{4}{*}{$\begin{array}{l}\text { Excessive weight in other } \\
\text { family members } \\
\text { (more than one answer could } \\
\text { be given) }\end{array}$} & Yes & $22(48)$ & $13(59)$ & $9(38)$ \\
\hline & No & $17(37)$ & $3(14)$ & $14(58)$ \\
\hline & I do not know & $6(13)$ & $5(23)$ & $1(4)$ \\
\hline & Not given & $1(2)$ & $1(4)$ & 0 \\
\hline \multirow{7}{*}{$\begin{array}{l}\text { Reasons of obesity } \\
\text { (more than one answer could } \\
\text { be given) }\end{array}$} & Poor physical activity & $40(87)$ & $18(82)$ & $22(92)$ \\
\hline & Unhealthy diet & $40(87)$ & $18(82)$ & $22(92)$ \\
\hline & Genetic factors & $22(48)$ & $10(46)$ & $12(50)$ \\
\hline & Medical conditions & $8(17)$ & $5(23)$ & $3(13)$ \\
\hline & Pace of life & $6(13)$ & $4(18)$ & $2(8)$ \\
\hline & Family problems & $10(22)$ & $4(18)$ & $6(25)$ \\
\hline & School problems & $5(11)$ & $2(9)$ & $3(13)$ \\
\hline \multirow{6}{*}{$\begin{array}{l}\text { Obesity consequences } \\
\text { (more than one answer could } \\
\text { be given) }\end{array}$} & Psychological problems & $30(65)$ & $13(59)$ & $17(71)$ \\
\hline & Social problems & $18(39)$ & $8(36)$ & $10(42)$ \\
\hline & Somatic disorders & $19(41)$ & $9(41)$ & $10(42)$ \\
\hline & Poor physical fitness & $30(65)$ & $13(59)$ & $17(71)$ \\
\hline & Unattractive look & $14(30)$ & $10(46)$ & $4(17)$ \\
\hline & Precocious death & $13(28)$ & $10(46)$ & $3(13)$ \\
\hline \multirow{6}{*}{$\begin{array}{l}\text { Most effective therapeutic } \\
\text { approach } \\
\text { (more than one answer could } \\
\text { be given) }\end{array}$} & Drugs & $1(2)$ & $1(5)$ & 0 \\
\hline & Implementation of healthy diet & $40(87)$ & $20(91)$ & $20(83)$ \\
\hline & Change in child's life style & $30(65)$ & $13(59)$ & $17(71)$ \\
\hline & Change in child's physical activity & $33(72)$ & $14(64)$ & $19(79)$ \\
\hline & Psychological help & $12(26)$ & $8(36)$ & $4(17)$ \\
\hline & Change in family life style & $22(47)$ & $11(50)$ & $11(46)$ \\
\hline
\end{tabular}


by boys' parents. Parents of girls emphasized psychological problems (17 parents, 71\%), poor physical fitness (17 parents, $71 \%$ ), social problems (10 parents, $42 \%$ ), and somatic disorders (10 parents, $42 \%)$. For boys' parents, the most important were psychological problems (13 parents, 59\%) and poor physical fitness (13 parents, $59 \%)$ but also unattractive look (10 parents, 46\%) and premature death (10 parents, $46 \%$ ). According to parents, the most effective therapeutic factors were to comply with diet (40 parents, $87 \%$ ), increase physical activity (33 parents, $72 \%$ ), and change of lifestyle of the child (30 parents, $65 \%$ ). The change of life style of the whole family is effective in the child's obesity therapy only according to $22(47 \%)$ parents, and psychotherapist help could be useful in opinion of $12(26 \%)$ parents.

Table 3 presents the results of FACES IV completed by children and parents. Significantly higher level of rigidity was declared in families by children compare to parents $(p=0.02)$, especially by boys $(p=0.002)$. Parents indicated higher level of enmeshment in the family than children; however, the difference did not reach the level of statistical significance $(p=0.06)$. No significant differences were found in cohesion, flexibility, communication, and satisfaction between the perception of children and parents. In most of studied subjects, the level of communication and satisfaction were average or high (Figure 1). The families were assessed as balanced according to 57\% of children and $30 \%$ of parents $(p=0.01)$. Also, cohesion index and main index were significantly higher in children's perception then parents' $(p=0.02, p=0.004)$. There were no significant correlations between FACES IV scales and indexes, and BMI of children and obesity occurrence in children and parents.

\section{Discussion}

In our research, we noticed significant difference between real parents' weight status and weight status they declare in questionnaire. Only $47 \%$ of responders gave the information in questionnaire of excessive weight in family members. In the same time, $74 \%$ of mothers and $82 \%$ of fathers were overweight or obese and $93 \%$ of obese children had at least one parent with excessive weight. It drove us to the conclusion that parents do not bind the fact of improper eating habits in the family with their obesity or they just deny this association. Incorrect eating behavior includes: not diversified and irregular meals, skipping breakfasts, eating in fast-food restaurants, eating in the absence of sensation of hunger, eating at night, snacking between meals, and eating during TV watching [5,6]. Lack of awareness or denying this phenomenon could lead to children obesity. Hood et al. [7] showed that increased risk of children obesity exists in the families, in which parents are not able to control their own diet, apply restrictive diets, or alternately apply both strategies. Extremely strong effect can be seen when excessive body weight is present in both parents [8,9]. The research by Keane et al. [9] on a big Irish 9-year-old children cohort showed that the most significant obesity predictor in child's obesity is obesity of parent, especially mother's, where father's body weight is less important. The mother is the main caregiver of the child, spending with him a lot of time and has the stronger influence on his eating behavior [8-10]. The child that is functioning in the obesogenic family, characterized with excessive caloric intake and low physical activity, acquires habits of this family [11].

Table 3. The results of questionnaire formulated on the basis of Family Adaptability and Cohesion Evaluation Scales (FACES IV) by D. Olson, Family Communication Scale and Family Satisfaction Scale performed in children and parents

\begin{tabular}{|l|c|c|c|c|c|c|}
\hline \multirow{2}{*}{} & \multicolumn{2}{|c|}{ Obese children, $n=46$} & \multicolumn{2}{c|}{ Boys, $n=22$} & \multicolumn{2}{c|}{ Girls, $n=24$} \\
\cline { 2 - 7 } & Children & Parents & Children & Parents & Children & Parents \\
\hline Cohesion & $28.5 \pm 3.0$ & $28.0 \pm 2.5$ & $28.5 \pm 2.5$ & $28.5 \pm 2.5$ & $28.5 \pm 4.0$ & $28.0 \pm 2.8$ \\
\hline Flexibility & $24.5 \pm 4.2$ & $24.3 \pm 4.3$ & $25.5 \pm 4.5$ & $25.1 \pm 3.3$ & $23.6 \pm 3.7$ & $23.6 \pm 4.9$ \\
\hline Disengagement & $13.0 \pm 3.5$ & $14.0 \pm 3.0$ & $12.0 \pm 3.5$ & $13.0 \pm 2.0$ & $14.5 \pm 3.3$ & $15.0 \pm 4.0$ \\
\hline Enmeshment & $14.6 \pm 4.8^{1}$ & $16.3 \pm 5.6$ & $15.4 \pm 4.4$ & $16.5 \pm 5.8$ & $13.9 \pm 5.1$ & $16.2 \pm 5.6$ \\
\hline Rigidity & $20.2 \pm 5.0^{2}$ & $18.0 \pm 4.1$ & $21.5 \pm 4.2^{3}$ & $18.0 \pm 3.9$ & $19.0 \pm 5.4$ & $18.1 \pm 4.3$ \\
\hline Chaos & $16.9 \pm 5.3$ & $18.3 \pm 5.1$ & $16.1 \pm 4.9$ & $18.7 \pm 5.8$ & $17.6 \pm 5.6$ & $18.0 \pm 4.4$ \\
\hline Communication & $40.0 \pm 5.5$ & $37.0 \pm 5.5$ & $39.5 \pm 3.5$ & $39.0 \pm 5.0$ & $40.0 \pm 6.3$ & $37.0 \pm 6.8$ \\
\hline Satisfaction & $41.0 \pm 4.5$ & $39.0 \pm 6.0$ & $40.0 \pm 4.0$ & $39.5 \pm 4.0$ & $41.5 \pm 5.5$ & $36.5 \pm 6.3$ \\
\hline Cohesion index & $1.0 \pm 0.4^{4}$ & $0.7 \pm 0.3$ & $1.1 \pm 0.5^{5}$ & $0.7 \pm 0.3$ & $0.9 \pm 0.4$ & $0.7 \pm 0.3$ \\
\hline Flexibility index & $0.9 \pm 0.2$ & $0.8 \pm 0.2$ & $0.9 \pm 0.2$ & $0.9 \pm 0.2$ & $0.9 \pm 0.2$ & $0.8 \pm 0.2$ \\
\hline General index & $1.0 \pm 0.4^{6}$ & $0.8 \pm 0.3$ & $1.0 \pm 0.4^{7}$ & $0.8 \pm 0.3$ & $1.0 \pm 0.4^{8}$ & $0.8 \pm 0.4$ \\
\hline
\end{tabular}

Children vs. parents: ${ }^{1} p=0.06,{ }^{2} p=0.02,{ }^{3} p=0.002,{ }^{4} p=0.02,{ }^{5} p=0.04,{ }^{6} p=0.004,{ }^{7} p=0.04,{ }^{8} p=0.05$ 

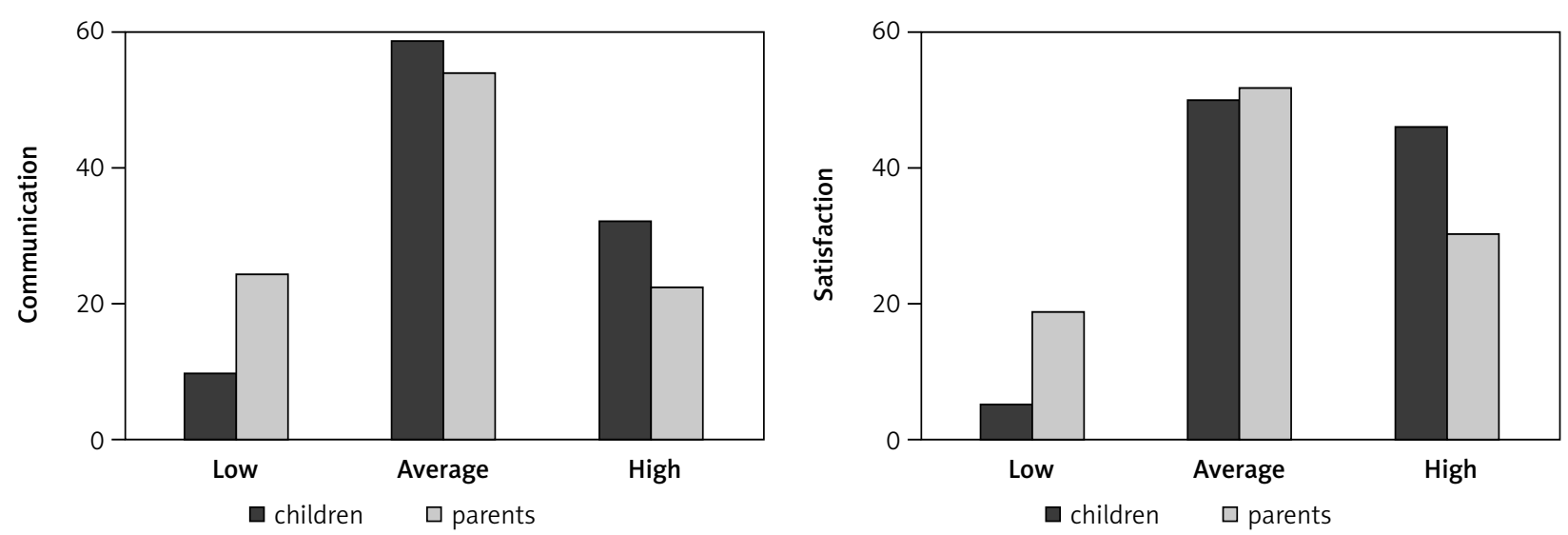

Figure 1. Distribution of low, average, and high results of communication and satisfaction in children [C] and parents [P]

Parents examined in our research, as a main reason of child's obesity gave unhealthy diet and poor physical activity as well other factors related to unhealthy life style. Family problems were given less frequently as a cause. However, other researches confirm that unhealthy eating behavior could be connected with incorrect family system functioning $[12,13]$. Negation of significant family problems could be related to the tendency of avoiding the sense of guilt associated to child's obesity. Lack of control of own weight, family problems, unwillingness of other family members to be on diet together with the child are considered as the main obstacles in the therapy of obese child [14].

According to parents, the most important consequences of childhood obesity are psychological problems and poor physical fitness. Interestingly, boy's parents underlined unattractive appearance and the risk of premature death, whereas girl's parents concentrated on social problems and risk of somatic disorders related to obesity. From the psychological perspective, stigmatization, depression, and low-quality of life are the main negative consequences of obesity. Whitherspoon et al. [15] showed worse social functioning in obese children compare to children with normal weight or overweight. Obese children had lower self-esteem, higher depression score, and lower self-perception of own body. Interestingly, it was not seen in overweight teenagers. It may be due to perception of overweight as a norm. Psychosocial functioning, especially decreased mood and own body perception was poorer in obese girls than in obese boys [15]. It is worth mentioning that in our research we assessed this phenomenon from the parents' point of view, and the child's perception of obesity consequences could be totally diverse.

It is highly alarming that less than half of parents saw the necessity of changing the life style of the whole family in the process of obese child therapy. Meanwhile, many researches showed that only the change of the life style of all family members could lead to proper eating behavior shaping acquired by child, however, it is very hard to accomplish [16]. The significance of this issue was presented by Pasztak-Opiłka [17]. In investigated cohort, in $89 \%$ of the families with obese child, the diet was implemented only to a child, but $75 \%$ of parents had excessive body weight. The obstacle in the treatment of obese child could be unhealthy, fixed eating behavior of parents who are also obese.

It is well known that better functioning of the family system is related to higher level of healthy eating behavior [18]. In our research, significantly more obese children, both girls and boys, assessed their family as well balanced (57\%) than parents did (30\%). Cyril et al. [19] also found the differences in family functioning assessment between children and their parents, however the relationship was reverted: children more often perceived the family as unbalanced than their parents. In general, in our group, children evaluated the family functioning better than parents, despite flexibility. Significantly higher level of rigidity was reported by children (especially boys) compared to parents. The rigidity is defined as insufficient ability to provide changes in the family: negotiations, roles, and rules changing in response to events or stress. It could be related to study group characteristics, especially age of children. It might be connected with adolescence period and behavior typical for this time of life. In the same time, parents assessed the families as more enmeshed than children did, independently from child's gender. Enmeshment is one of the dimensions of family cohesion. It depicts the situation in family life, when coalitions can appear and too high level of dependence of each other in the field of hobbies, leisure time spending, and relations to the persons who is not a family member. It could lead to a situation that the family members stay together, even though they do not want to be the family any longer. Parents may be aware of the problems in the family but these problems are perceived as not very important by teenagers or parents hide the problems from children.

Parents examined in our research perceived lower level of family cohesion than children, especially boys. 
Similar relations were observed by Nascimento et al. [13] who assessed the children's quality of life from the parents' perspective. He found that parents of obese or overweight children judge the family as less coherent. The average levels of family cohesion and flexibility, high level of communication, and satisfaction of family functioning favor healthy lifestyle and eating behavior [12]. No significant differences were found in the assessment of communication and satisfaction between the children group and parents' group, and in most of studied subjects, the level of communication and satisfaction were average or high. Communication in the family correlates positively with engagement in heathy behavior, especially in healthy eating, whereas problems with communication could be the main obstacle in the therapeutic process $[12,20]$.

\section{Conclusions}

Our research showed that majority of children had at least one overweight or obese parent. Significant difference between objective parents' body mass and declared obesity presence in the family was observed. Most of the parents had the vast knowledge about causes and consequences of obesity but they did not see any relationship between their own eating disturbances with excessive body weight.

Most parents underlined the need of change only in child's functioning, but they did not see the need of change of their own habits, what was shown by many researchers, is the condition essential to effective therapy of childhood obesity. Such attitude may be associated with lower evaluation of family system functioning and lower cohesion given by parents comparing to children's assessment, and may be related to lack of faith in the possibility of making changes in family system. However, communication and family life satisfaction were assessed at the average and high level by both parents and children. Good communication and family life satisfaction are important recourses in the process of obesity therapy.

The study limitation is a relatively small sample size to demonstrate reliable estimates for several independent variables as well as to determine the inability to detect further subtle changes. Further investigations with a larger cohort of dyads are planned in the future to validate reliable conclusions.

\section{Disclosure}

The authors report no conflict of interest.

\section{References}

1. Roth CL, Jain V. Rising Obesity in Children: A Serious Public Health Concern. Indian J Pediatr 2018; 85: 461-462.

2. August GP, Caprio S, Fennoy I, et al. Prevention and treatment of paediatric obesity: an endocrine society clinical practice guide- line based on expert opinion. J Clin Endocrinol Metab 2008; 93: 4576-4599.

3. Margasinski A. Family in Circumplex Model and FACES IV by David H. Olson. Nowiny Psychologiczne 2006; 4: 69-87.

4. Olson DH, Gorall DM. Faces IV and the Circumplex model. Life Innovations, Minneapolis 2006; 1-20.

5. Gowey MA, Reiter-Purtill J, Becnel J, et al.; TeenView Study Group. Weight-related correlates of psychological dysregulation in adolescent and young adult (AYA) females with severe obesity. Appetite 2016; 99: 211-218.

6. Cichecka-Wilk M. Eating behaviour in children with simple obesity in own experience. Lubelski Rocznik Pedagogiczny 2015; 32: 243-275.

7. Hood MY, Moore LL, Sundarajan-Ramamurti A, et al. Parental eating attitudes and the development of obesity in children. The Framingham Children's Study. Int J Obes Relat Metab Disord 2010; 24: 1319-1325.

8. Gibson LY, Byrne SM, Davis EA, et al. The role of family and maternal factors in childhood obesity. Med J Aust 2007; 186: 591-595.

9. Keane E, Layte R, Harrington J, Kearney PM, Perry IJ. Measured parental weight status and familial socio-economic status correlates with childhood overweight and obesity at age 9. PLoS One 2012; 7: 43503.

10. Scaglioni S, Salvioni M, Galimberti C. Influence of parental attitudes in the development of children eating behavior. Br J Nutr 2008; 99: 22-25.

11. Swinburn B, Egger G, Raza F. Dissecting obesogenic environments: the development and application of a framework for identifying and prioritizing environmental interventions for obesity. Prev Med 1999; 29: 563-570.

12. Mróz J, Kaleta K. Relation structure in the parent family and healthy behavior in adulthood. Problemy Higieny i Epidemiologii 2013; 94: 239-246.

13. Nascimento MMR, Melo TR, Pinto RMC, et al. Parents' perception of health-related quality of life in children and adolescents with excess weight. Jornal de Pediatria 2015; 92: 65-72.

14. Uzark KC, Becker MH, Dielman TE, et al. Perceptions held by obese children and their parents: implications for weight control intervention. Health Educ Q 1998; 15: 185-198.

15. Whitherspoon D, Latta L, Wang Y, Black M.M. Do depression, self-esteem, body-esteem and eating attitudes vary by BMI among African American adolescents? J Pediatr Psychol 2013; 38: $1112-1120$.

16. Moore ES, Wilkie WL, Desrochers DM. All in the Family? Parental Roles in the Epidemic of Childhood Obesity. J Consum Res 2016; 43: 824-859.

17. Pasztak-Opitka A. Psychosocial dimensions of childhood and adolescent obesity and possibility of an effective intervention. I National Meeting: "Obesity and children and adolescent - from causes to consequences. The role of bariatric surgery". Katowice 2016, 19-20.09.2016.

18. Haines J, Rifas-Shiman SL, Horton NJ, et al. Family functioning and quality of parent-adolescent relationship: cross-sectional associations with adolescent weight-related behaviors and weight status. Int J Behav Nutr Phys Act 2016; 13: Article ID 68.

19. Cyril S, Halliday J, Green J, Renzaho AMN. Relationship between body mass index and family functioning, family communication, family type and parenting style among African migrant parents and children in Victoria, Australia: a parent-child dyad study. BMC Public Health 2016; 16: 707.

20. Boutelle KN, Feldman S, Neumark-Sztainer D. Parenting an overweight or obese teen: issues and advice from parents. J Nutr Educ and Behav 2012; 44: 500-506. 